\title{
Artículos
}

\section{Los límites de la recaudación predial en los municipios urbanos de México: un estudio de casos}

\section{The limits of property tax collection in the urban municipalities of Mexico: A case study}

\author{
Mónica Unda Gutiérrez*
}

\section{Resumen}

El nivel de recaudación tributaria está determinado por factores económicos, politicos y de capacidad institucional. El objetivo de este trabajo es analizar el poder explicativo de los últimos dos sobre la recaudación predial. Para ello se llevó a cabo un estudio de casos en seis municipios urbanos, lo que permite observar los mecanismos que están detrás de los factores que influyen en el nivel de recaudación predial. Se condujeron más de treinta entrevistas semiestructuradas con funcionarios municipales y se midió la capacidad institucional para el cobro del predial de las tesorerías y los catastros. Los hallazgos principales demuestran, por un lado, que a mejores niveles de recursos humanos, materiales y tecnológicos (mayor capacidad institucional), mayor es la recaudación. Y, por otro lado, que los alcaldes, tesoreros y directores del catastro deciden generalmente no subir las tasas, tampoco actualizar valores catastrales ni capitalizar las actualizaciones para aumentar la recaudación porque juzgan que tales medidas tendrán un costo político que no quieren pagar.

Palabras clave: predial; capacidad institucional; finanzas municipales; economía política de los impuestos.

\footnotetext{
Abstract

Tax collection levels are determined by economic, political and institutional capacity factors. The purpose of this paper is to analyze the explanatory power of the last

* Profesora investigadora de El Colegio de México, A.C., Centro de Estudios Demográficos, Urbanos y Ambientales. Dirección postal: Carretera Picacho Ajusco, núm. 20, Ampliación Fuentes del Pedregal, Tlalpan, 14110, Ciudad de México, México. Correo electrónico: munda@, colmex.mx
} 
two on property tax collection. To this end, a case study was carried out in six urban municipalities, making it possible to observe the mechanisms behind the factors influencing the level of property tax collection. Over thirty semi-structured interviews were conducted with municipal officials and the institutional capacity for property tax collection of the treasuries and land registers was measured. The main findings show, on the one hand, that the better the levels of human, material and technological resources (greater institutional capacity), the greater the tax collection. They also revealed the fact that mayors, treasurers and directors of land registers usually decide not to raise rates, or to update cadastral values or capitalize updates in order to increase tax collection because they believe that these measures will entail a political cost they are unwilling to pay.

Keywords: property tax; institutional capacity; municipal finances; political economy of taxes.

\section{Introducción}

El municipio mexicano ha cambiado mucho desde principios de los años ochenta, cuando inició el proceso de descentralización fiscal. Si bien los cambios propiciados por este proceso y la democratización han tenido un impacto diferenciado en los municipios del país, éstos ahora están sujetos a la competencia política y a un tipo de relaciones intergubernamentales muy distintos de los que primaban hace más de tres décadas. A pesar de estos cambios, el municipio no ha logrado aumentar su autonomía económica como se tuvo en mente al proponerse la reforma del artículo 115 constitucional en 1982 (Silva-Herzog, 1982). Desde entonces, se le delegó la potestad sobre los impuestos inmobiliarios y se establecieron sus responsabilidades de gasto. No obstante, el potencial de recaudación de los municipios, especialmente a través del predial, ha sido desaprovechado en la mayoría de éstos. En la actualidad, la hacienda municipal depende en 70\% de las transferencias de la federación y los estados, sólo $21 \%$ proviene de ingresos propios (impuestos, derechos, productos y aprovechamientos), y el predial contribuye en apenas $8.8 \%$ a los ingresos públicos de la hacienda local (véase la Gráfica 1).

Si bien la recaudación predial ha aumentado ligeramente desde que está en manos de los gobiernos locales, tanto en términos reales y como proporción del producto interno bruto (PIB) (véase la Gráfica 2), lo que se extrae por este impuesto está muy lejos de lo que recaudan otros países latinoamericanos y de la OCDE (Organización para el Desarrollo Económico) (véase la Gráfica 3). 


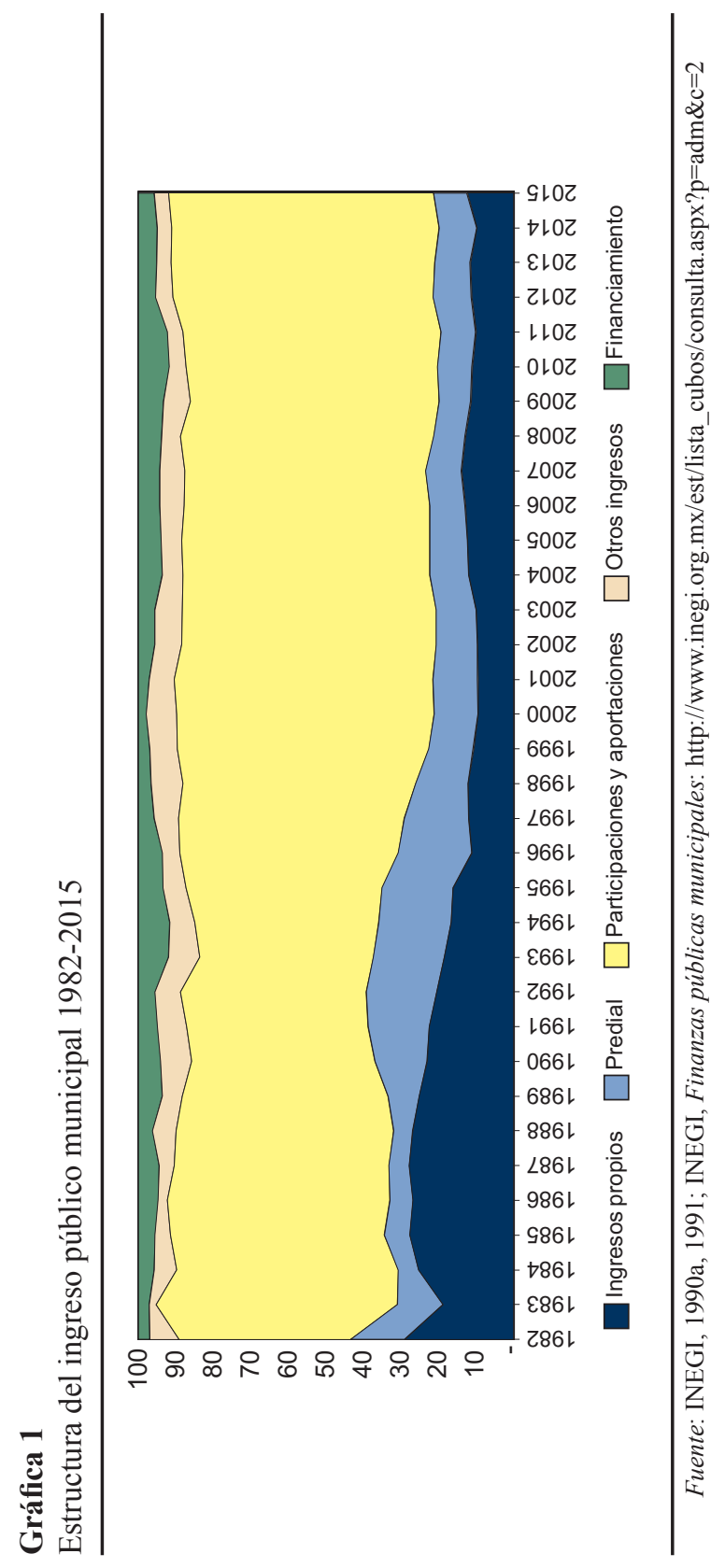




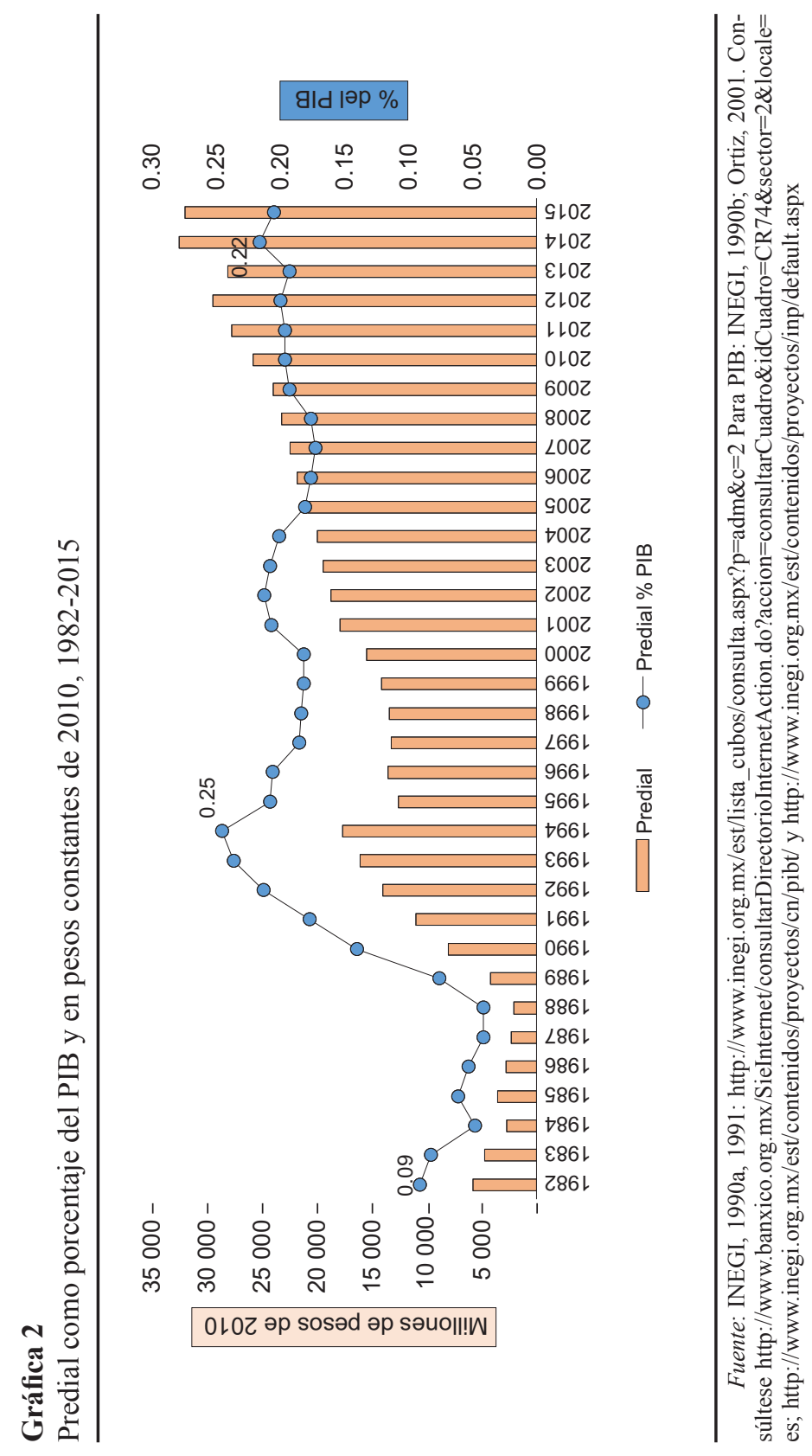




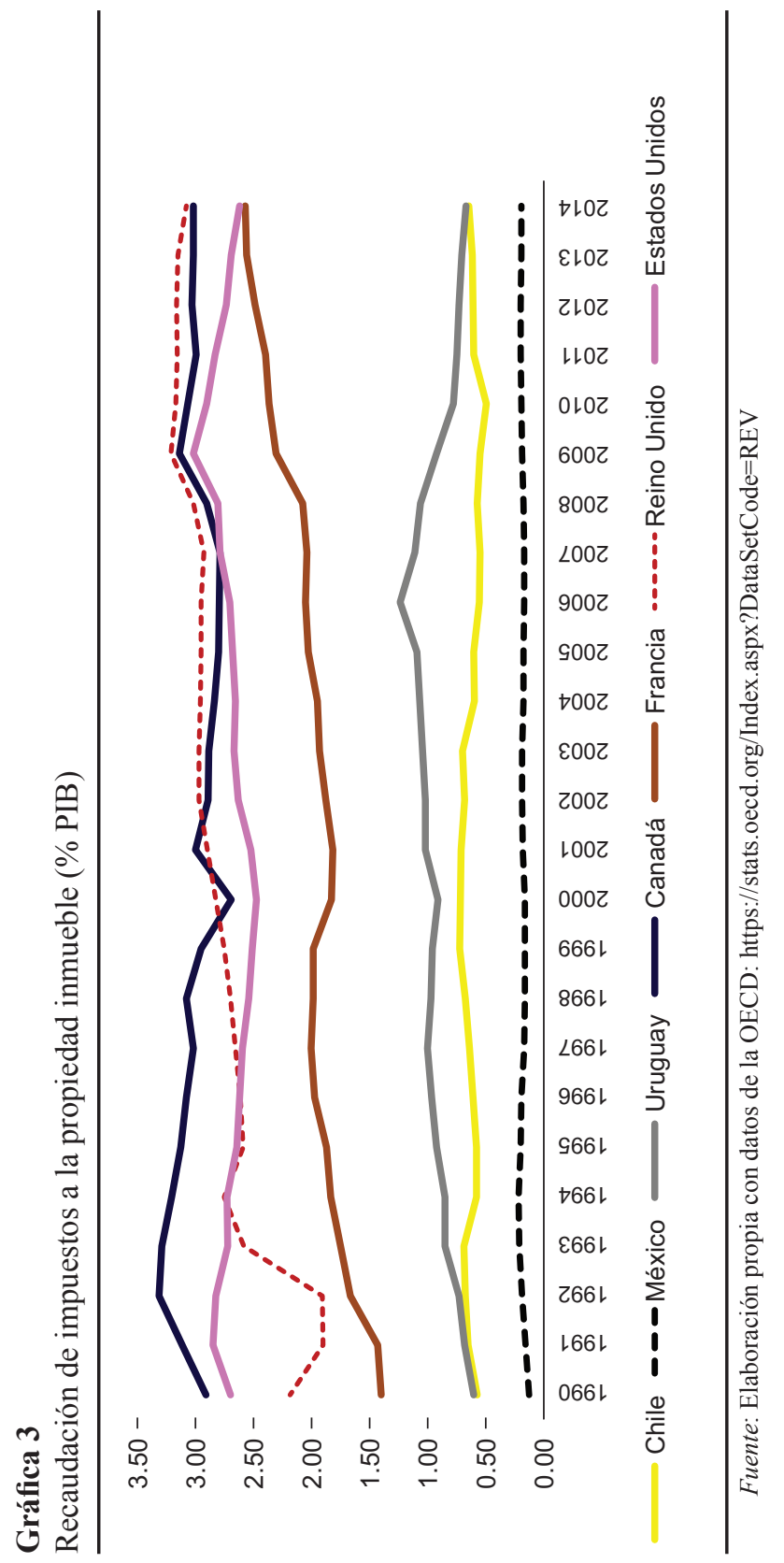


En los últimos cinco años, México ha recaudado en promedio $0.20 \%$ del PIB, mientras que Reino Unido, Estados Unidos, Uruguay y Chile han recaudado $3.15,2.76,0.73$ y $0.59 \%$, respectivamente. Una de las constantes de la hacienda municipal ha sido la baja recaudación predial. Por ello, y considerando la necesidad de aumentar recursos para hacer frente a los déficits sociales y de infraestructura en las ciudades del país, es que es relevante preguntarse ¿por qué la recaudación predial es tan baja? y ¿qué factores influyen en el nivel de recaudación predial?

Las preguntas de este tipo, interesadas en entender los niveles de recaudación, han sido tratadas por la literatura, que sugiere tres tipos de determinantes: los económicos, los políticos y los administrativos o de capacidad institucional. Todos estos factores plantean límites a la recaudación de impuestos como el predial. El objetivo de este trabajo es explorar la capacidad explicativa sólo de los últimos dos. La investigación toma como punto de partida los hallazgos de estudios de corte estadístico (Ibarra y Sotres, 2009 y 2014; Unda y Moreno, 2015; Unda, 2017) que establecen la importancia de los factores económicos para comprender la recaudación predial, pero considera que tales factores no bastan para explicar los montos que se recaudan. Se propone que la capacidad institucional de los gobiernos municipales y los factores políticos son variables que pueden dar mayor luz sobre el nivel de recaudación.

Con objeto de explorar estas variables explicativas se llevó a cabo un estudio de casos, para lo que se eligieron seis municipios urbanos, representativos de los 50 municipios más poblados del país que han experimentado alternancia política y tienen un nivel de desarrollo por encima del promedio nacional. Un small-n study como éste hace posible determinar con mayor detalle los mecanismos que están detrás de los factores que directamente influyen en el nivel de recaudación predial. Un estudio de casos, por el nivel de observación que permite, ofrece una mayor precisión para medir variables independientes de corte político y de capacidad institucional. Las entrevistas que se condujeron a tesoreros, directores de catastro y de ingresos dejan ver las variables que influyen en las decisiones de estos funcionarios para diseñar el impuesto y para cobrarlo. Igualmente, la aplicación de un instrumento de medición de capacidad institucional en las tesorerías y catastros de estas seis ciudades permite valorar qué tan relevante es ésta para la recaudación y por qué.

Los hallazgos principales demuestran que la capacidad institucional y las consideraciones políticas son factores que explican el nivel de recaudación predial en los municipios urbanos más poblados del país. Por un lado, a mejores niveles de recursos humanos, materiales y tecnológicos (mayor 
capacidad institucional) en el municipio, mayor es la recaudación de este impuesto. Por otro lado, se concluye que los alcaldes, tesoreros y directores de catastro deciden generalmente no subir las tasas, tampoco actualizar valores catastrales ni capitalizar las actualizaciones para aumentar la recaudación porque juzgan que tales medidas tendrán un costo político que no quieren pagar. Los hallazgos de este trabajo, basados en evidencia cualitativa, complementan estudios previos (Unda, 2017) apoyados en análisis estadísticos que consideran a todos los municipios del país, que igualmente concluyen que las variables políticas influyen en el nivel de recaudación. ${ }^{1}$

Este estudio realiza varias contribuciones al conocimiento, pues sus hallazgos contribuyen a llenar un vacío en la literatura en vista de lo poco que se han estudiado las variables de corte no económico para explicar el predial. ${ }^{2}$ Una aportación metodológica puntual del trabajo es la medición de la capacidad institucional del municipio para cobrar el predial a través de dos instrumentos de medición aplicados a las tesorerías y catastros. Por último, los hallazgos de este trabajo son útiles para informar a quienes toman decisiones sobre tal impuesto. Mediante la observación a profundidad y el seguimiento cercano al proceso del cobro del predial en estos municipios se puede mostrar con claridad la lógica con la que trabajan los gobiernos municipales en el tema impositivo. Estos hallazgos pueden ser traducidos en recomendaciones útiles para las administraciones municipales que busquen mejorar el desempeño y la recaudación de su predial. En un contexto de presión por recentralizar las potestades fiscales del municipio, como busca el actual gobierno federal (2012-2018), ${ }^{3}$ y bajo una tendencia a transferir menores recursos federales a los gobiernos locales, mejorar los ingresos de los municipios es una necesidad apremiante.

El artículo se divide en cinco secciones más. La siguiente desarrolla el marco teórico que guía el trabajo. La tercera sección explica la selección de

${ }^{1}$ El citado estudio concluye, entre otras cosas, que los municipios que enfrentan mayor competencia electoral tienden a no incrementar la recaudación predial. Lo que sugiere que los funcionarios municipales, al percibir mayor probabilidad de perder las elecciones, prefieren comportarse de manera populista y no aumentar la recaudación. Esta conclusión es coincidente también con los hallazgos de Broid (2010).

${ }^{2}$ Los estudios disponibles sobre el predial son los de Ibarra y Sotres (2009; 2013; 2014), quienes realizan su análisis sobre diversos estados de la frontera norte; Bustamante (2001), que se concentra en la ciudad de Hermosillo; Raich (2001), quien analiza los municipios de Puebla; Zúñiga (2010) y Canavire y Zúñiga (2015), que estudian los municipios de Sinaloa; Cruz (2011), que investiga el predial en Oaxaca; y Ruelas (2010), quien considera a la totalidad de los municipios del país.

${ }^{3}$ Un ejemplo de la inclinación del gobierno federal por la recentralización fiscal se demuestra en la reforma de 2013 a la Ley de Coordinación Fiscal, modificada para ofrecer incentivos (mayores participaciones) a los municipios que firmen convenios para ceder la administración del predial a sus gobiernos estatales. 
los casos de estudio y describe la situación del predial en estos municipios. El apartado cuarto busca determinar si existe una relación positiva entre la capacidad institucional de los municipios y su recaudación predial, para lo que se mide la capacidad institucional de los catastros y las direcciones de ingreso. Posteriormente, con el fin de detectar la influencia de los factores políticos en la recaudación predial, se propone que el nivel de recaudación depende de los valores catastrales, las tasas impositivas y los gastos fiscales. Así, el objetivo de esta sección es presentar y analizar la evidencia que permite entender mejor qué hay detrás de cada uno de estos tres factores. El último apartado contiene las conclusiones.

\section{Los determinantes de la recaudación tributaria sugeridos en la literatura}

Las preguntas sobre el nivel de recaudación y composición tributaria han sido abordadas por la literatura desde distintas perspectivas. Según Di John (2006), éstas se pueden agrupar en tres enfoques: el económico, el de economía política, y el administrativo o de capacidad institucional.

El enfoque económico establece que los determinantes del nivel de recaudación son las variables económicas (Hinrichs, 1966; Musgrave, 1969; Lotz y Morss, 1970). Se plantea que la producción, el ingreso, los recursos alternos (como transferencias o deuda), el nivel de urbanización o el tamaño del sector agrícola son variables que delimitan la capacidad recaudadora. Definitivamente, indicadores económicos de este tipo marcan el límite y/o potencial para la recaudación. Sin embargo, este enfoque se queda corto para explicar el que países, estados o municipios con variables económicas similares presenten niveles de recaudación distintos. Es aquí donde el enfoque de economía política puede aportar a la explicación y ayudar a dilucidar la complejidad de los procesos políticos y sociales que están detrás del nivel de recaudación de un gobierno.

En el caso del predial en México, los estudios que han tratado el tema descansan en argumentos de corte económico. Estos trabajos han sugerido que el bajo nivel de recaudación municipal tiene que ver con las transferencias de recursos que reciben del gobierno federal (Sour, 2004, 2008; Canavire y Zúñiga, 2015; Zúñiga, 2010). ${ }^{4}$ Argumentan que las transferencias

${ }^{4}$ De estos trabajos, sólo Sour (2008) analiza la totalidad de los municipios del país y únicamente Canavire y Zúñiga (2015) y Zúñiga (2010) se concentran en la relación entre la recaudación predial y las transferencias. Sour analiza el esfuerzo fiscal (ingresos propios) en ambos trabajos (2004 y 2008). 
federales, es decir, las participaciones (ramo 28) y las aportaciones (ramo 33 ), tienen un efecto pernicioso sobre la recaudación de impuestos locales, pues han ocasionado que los gobiernos subnacionales sean altamente dependientes de esos recursos y los han desincentivado para mejorar el cobro de impuestos como el predial. Si bien esto tiene sentido, estudios empíricos más recientes que consideran a todos los municipios del país a lo largo de los últimos veinte años (Unda y Moreno, 2015; Unda, 2017) contradicen esta tesis al concluir que las transferencias se relacionan positivamente con la recaudación predial. ${ }^{5}$ Esto puede ser fruto de los cambios en las fórmulas de distribución de los fondos de transferencias que buscan neutralizar los efectos negativos que dichos recursos pudieran tener en la recaudación municipal.

El enfoque de economía política parte de la idea de que los impuestos son un problema político, pues al ser impopulares por naturaleza, requieren de la construcción de consensos entre el gobierno y la sociedad. Dentro de esta perspectiva se enfatizan variables como el poder de los grupos de interés para poder explicar el nivel y tipo de recaudación. Para algunos, la capacidad deliberada de cierto grupo de interés para limitar o modificar las opciones de otros, es decir con poder, es lo que define la manera de extraer recursos por parte del Estado. Para Best (1976), por ejemplo, la estructura impositiva refleja la distribución de poder en la sociedad, ya que supone que aquellos que tienen poder tendrán mayor influencia en el Estado y, por consiguiente, en la política tributaria.

El tercer enfoque considera que la baja recaudación tiene que ver con la falta de capacidad administrativa/institucional de las autoridades (Bird y Casanegra, 1992; Tanzi, 2000; Burgess y Stern, 1993). Una administración débil, con poca experiencia al respecto y con sistemas de contabilidad, información y control inadecuados es la razón de los bajos ingresos tributarios. Esta perspectiva enfatiza, sobre todo, la eficiencia y la efectividad de los gobiernos para cobrar impuestos.

Siendo que el trabajo se aprovecha de este marco teórico y busca explorar las variables de corte político y administrativo, es necesario apuntar lo que entenderemos por capacidad institucional y lo que significa la construcción de la misma. Primero, entendemos por capacidad institucional "la habilidad para desempeñar tareas de una manera efectiva, eficiente y sostenible" (Hilderbrand y Grindle, 1997, p. 34). Segundo, la construcción de capacidad institucional implica hacer énfasis en el proceso de construcción de esta capacidad: en las habilidades o componentes que son necesarios para que un

${ }^{5}$ Cabe señalar que los funcionarios entrevistados, como directores de ingreso y tesoreros, no reconocen que las transferencias estén desincentivando la recaudación predial. En su opinión, los recursos nunca están de más. 
gobierno desempeñe sus tareas. Según Daud et al. (2008), algunos de estos componentes son: i) el desarrollo de los recursos humanos; ii) el desarrollo de la organización, que considera las estructuras de gestión, así como los procesos y procedimientos internos y externos; iii) el marco jurídico e institucional; y $i v$ ) el desarrollo de las funciones de apoyo relacionadas con la tecnología, las tecnologías de la información y la comunicación.

Teniendo en mente lo anterior, la capacidad institucional de los gobiernos municipales será medida en función de los componentes que sean requeridos para que los gobiernos logren un objetivo en particular: el aumento de la recaudación predial. Para medir la capacidad institucional se construyeron dos instrumentos a aplicar en las tesorerías y catastros, mismos que se explican a detalle en la sección cuarta.

\section{El predial en los municipios seleccionados}

Esta sección tiene dos objetivos: explicar el proceso de selección de los casos de estudio y proponer un ranking de recaudación predial per cápita que considere el efecto de los valores inmobiliarios en cada una de estas seis ciudades. Es decir, se busca aislar el efecto de que en algunas ciudades la recaudación es mayor debido a que ahí los valores de suelo per se son más altos.

Los seis municipios elegidos provienen del universo de los 50 municipios más poblados del país que concentran $34 \%$ de la población nacional. Los 50 municipios más poblados contaban, según los datos proporcionados por la Unidad de Coordinación de Entidades Federativas (UCEF) de la Secretaría de Hacienda y Crédito Público (SHCP), con 24894755 cuentas prediales en 2013, lo que representa $37 \%$ del padrón predial nacional. La selección de los seis municipios se controló por nivel socioeconómico y por la variable de competencia política. Los seis están por encima del promedio nacional de Índice de Desarrollo Humano Municipal (IDHM) de 2005 y han tenido alternancia política al menos una vez desde inicios de los años 2000; asimismo, presentan variación en su nivel de recaudación predial per cápita y en su nivel de transferencias federales per cápita. ${ }^{6}$ Los criterios de selección se resumen en el Cuadro 1. Debido a estos criterios de selección, los hallazgos del estudio son representativos para los 50 municipios más poblados del país que han experimentado alternancia y un desarrollo por encima del promedio.

${ }^{6}$ Para definir los rangos de alto, medio y bajo, tanto en la variable dependiente (predial per cápita) como independiente (transferencias per cápita), se ordenó la muestra de los 50 municipios de mayor a menor y se dividió en tres grupos (alto, medio, y bajo). 


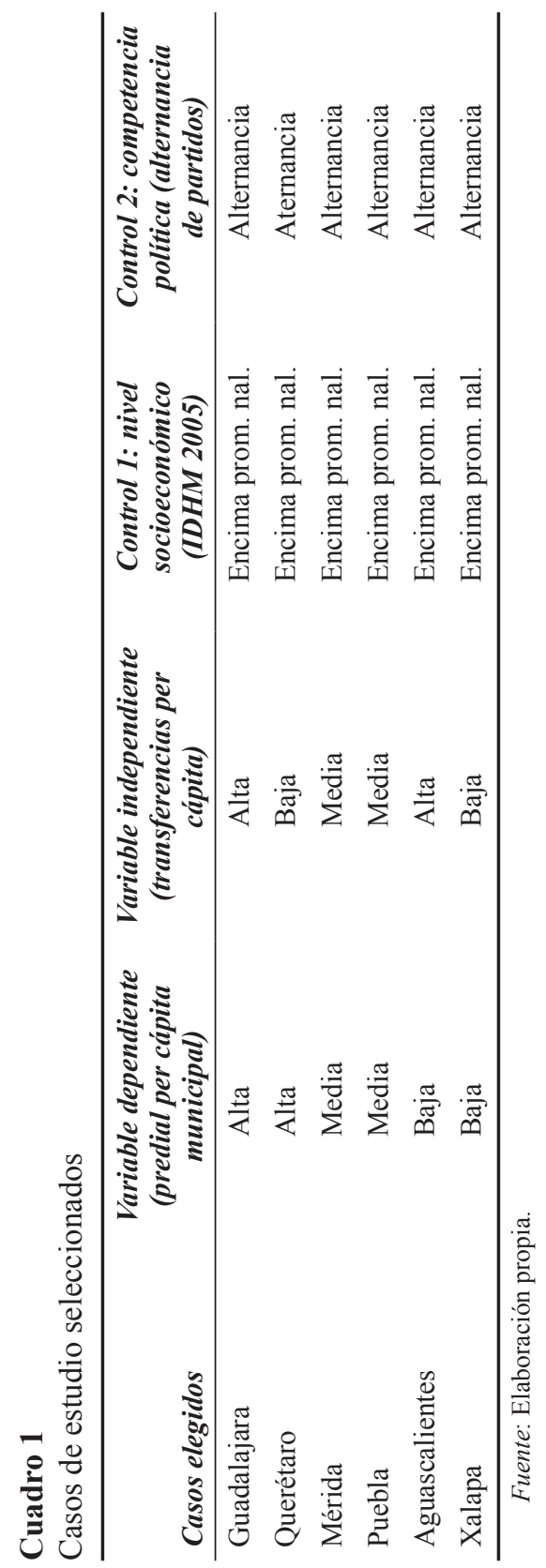


La pareja de municipios de alta recaudación predial son Querétaro y Guadalajara, que en 2010 recaudaron 418 y 383 pesos por habitante y se colocan en el mapa de las capitales estatales en segundo y tercer lugar (véase la Gráfica 4). Mérida y Puebla son la pareja de nivel medio de recaudación: ambos recaudaron 235 y 195 pesos respectivamente. Xalapa y Aguascalientes son el dúo de bajos recaudadores, con 160 y 155 pesos por habitante, y ocupan el lugar 22 y 23 de las 31 capitales.

Sin embargo, estos datos de recaudación predial llevan consigo el valor intrínseco de los inmuebles en cada ciudad. Es decir, cargan con el hecho de que el mismo bien inmueble, en igualdad de características, es más caro en Guadalajara que en Mérida, por ejemplo. Por ello, proponemos un nuevo ranking que aísle el efecto de los valores intrínsecos de cada ciudad y tenga el potencial de evidenciar otras variables que entran en juego para explicar la recaudación.

Lo ideal sería ver el diferencial entre los valores catastrales del mismo tipo de inmueble en diferentes municipios, pero no se cuenta con tales datos. Lo que sí se tiene son los valores de mercado del metro cuadrado de construcción de inmuebles con las mismas características en los seis municipios. ${ }^{7}$

El Cuadro 2 muestra los precios de mercado por metro cuadrado de construcción en los tipos de vivienda más comunes de los municipios: casa habitación de clase interés social y casa habitación clase media. Se calculan los índices de precios comerciales de ambos tipos de vivienda para poder apreciar con claridad qué porcentaje del metro cuadrado de construcción del municipio con mayor valor representa los metros cuadrados de construcción del mismo tipo de vivienda en otros municipios. Así, por ejemplo, el valor del metro cuadrado de construcción de una casa habitación de interés social en Mérida es $72 \%$ del valor del mismo tipo de inmueble en Querétaro, que tiene el valor más alto en este tipo. Los datos provienen de la base de datos en línea de la Sociedad Hipotecaria Federal (SHF). ${ }^{8}$

Querétaro y Guadalajara, que son la pareja que más predial por habitante recaudan, tienen también los precios de mercado de inmuebles más altos. Según el índice global, que es el promedio del índice para las casas habitación de interés social y medio, estos dos municipios tienen el índice más alto: 82.3 y 97.9, respectivamente. Xalapa y Mérida llaman la atención puesto

${ }^{7}$ La limitación de usar los valores de mercado como referencia es que éstos pueden estar lejos de los valores catastrales; este diferencial también es distinto en cada municipio.

8 Esta base de datos se compone de los avalúos que las unidades de valuación inscritas en el padrón de la SHF hicieron en el año en cada estado, municipio y código postal. Para conocer los datos que la SHF ofrece, véase: http://www.shf.gob.mx/estadisticas/EstadVivInformaAvaluos/Paginas/default.aspx 


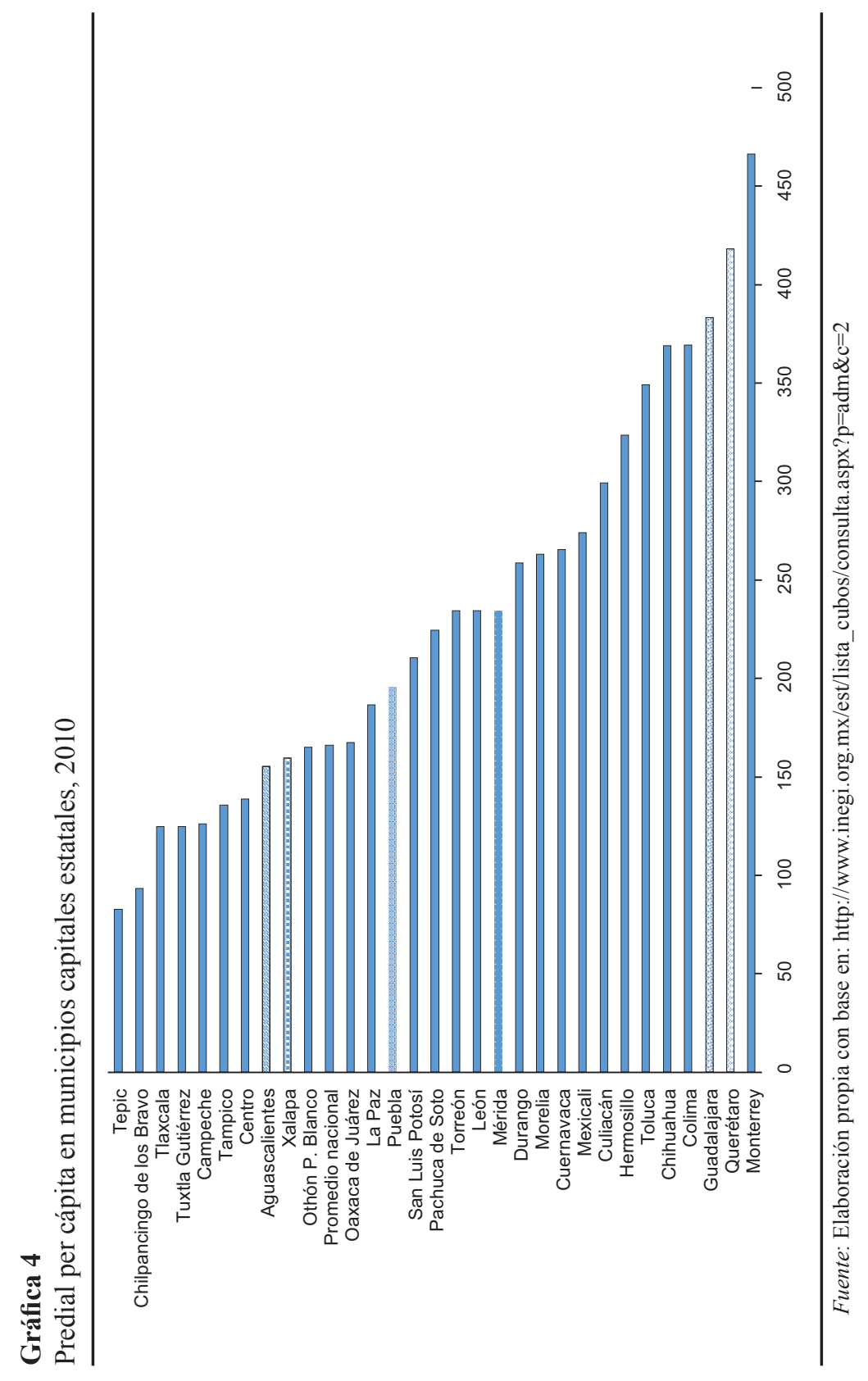




\section{Cuadro 2}

Precios de mercado promedio por metro cuadrado de construcción en 2014

\begin{tabular}{lccccc}
\hline & $\begin{array}{c}\text { Casa } \\
\text { habitación } \\
\text { interés social } \\
\text { (pesos) }\end{array}$ & Índice & $\begin{array}{c}\text { Casa } \\
\text { Mabitación } \\
\text { medio(pesos) }\end{array}$ & Índice & $\begin{array}{c}\text { Índice } \\
\text { global }\end{array}$ \\
\hline Querétaro & 7929 & 100 & 9495 & 65 & 82.3 \\
Guadalajara & 7604 & 96 & 14685 & 100 & 97.9 \\
Xalapa & 7271 & 92 & 8077 & 55 & 73.4 \\
Puebla & 6872 & 87 & 8165 & 56 & 71.1 \\
Aguascalientes & 6037 & 76 & 7158 & 49 & 62.4 \\
Mérida & 5713 & 72 & 6567 & 45 & 58.4 \\
\hline
\end{tabular}

Fuente: Elaboración propia con datos de SHF.

que el primero tiene un índice promedio de 73 , pero su recaudación es la penúltima más baja; ${ }^{9}$ y en cambio Mérida tiene un índice promedio de 59, el más bajo de los seis, pero tiene el tercer lugar de recaudación. Esto sugiere, de manera intuitiva, que Mérida está haciendo un esfuerzo "extra" para recaudar más, considerando que es el que tiene el valor más bajo entre los seis municipios en valores comerciales por metro cuadrado. Xalapa, al contrario, parece que no está capitalizando los valores comerciales más altos con que cuenta.

Una manera de apreciar el efecto que tiene la variación de los valores comerciales en la recaudación es aplicando el índice global del valor comercial de los dos tipos de inmuebles más comunes a la recaudación predial de cada uno. El Cuadro 3 nos lo muestra y propone un nuevo ranking en la recaudación de los casos de estudio. Querétaro y Mérida serían los que más recaudan (508 y 402 pesos, respectivamente), seguidos por Guadalajara y Puebla (391 y 275 pesos), y como los más bajos recaudadores estarían Aguascalientes y Xalapa con 249 y 218, respectivamente.

A partir de estos cálculos se puede decir que una vez que se neutraliza el hecho de que el metro construido en Mérida es el más barato y el de Guadalajara el más caro, la recaudación en Guadalajara ya no es la más alta de los seis casos, sino está en tercer lugar, mientras Mérida se vuelve el segundo mejor recaudador. El Cuadro 3, en síntesis, sugiere que Mérida, Aguas-

9 Es decir, el valor promedio del metro cuadrado de construcción en las casas habitación de interés social y clase media en Xalapa es de $74 \%$ de los inmuebles equivalentes en Guadalajara y Querétaro. 


\section{Cuadro 3}

Recaudación predial per cápita controlando por la diferencia en valores comerciales entre municipios

\begin{tabular}{|c|c|c|c|}
\hline Municipio & $\begin{array}{c}\text { Predial } \\
\text { per cápita } 2010\end{array}$ & $\begin{array}{c}\text { Recaudación } \\
\text { predial per cápita } \\
\text { aislando efecto } \\
\text { de valores } \\
\text { comerciales }\end{array}$ & $\begin{array}{c}\text { Recaudación } \\
\text { predial }\end{array}$ \\
\hline Querétaro & 418 & 508 & Alto \\
\hline Guadalajara & 383 & 391 & Medio \\
\hline Mérida & 235 & 402 & Alto \\
\hline Puebla & 195 & 275 & Medio \\
\hline Xalapa & 160 & 218 & Bajo \\
\hline Aguascalientes & 155 & 249 & Bajo \\
\hline
\end{tabular}

Fuente: Elaboración propia con datos de SHF e INEGI <http://www.inegi.org.mx/est/ lista_cubos/consulta.aspx? $\mathrm{p}=\mathrm{adm} \& \mathrm{c}=2>$.

calientes y Puebla realizan algún esfuerzo "extra” para recaudar más. Y por el contrario, la recaudación per cápita alta de Guadalajara responde a que el metro construido ahí es per se más caro que en los otros cinco municipios.

\section{La capacidad institucional y el desempeño recaudatorio}

Este apartado busca determinar si existe una relación positiva entre la capacidad institucional de los municipios y su recaudación predial. Para ello se mide la capacidad institucional de los catastros y las direcciones de ingreso en los seis casos de estudio. Como complemento de esta medición, hacia el final del apartado se resaltan las opiniones que los funcionarios entrevistados tienen sobre aspectos fundamentales de la capacidad institucional, como son los recursos humanos y materiales, y los procesos de gestión de recaudación.

A partir de las definiciones de capacidad institucional esbozadas antes, podemos abreviar que la capacidad institucional indica la habilidad de un gobierno para alcanzar sus objetivos, y que es igualmente importante entender y analizar cómo se construye esa capacidad. Es decir, de qué elementos es que se vale un gobierno para lograr determinado objetivo. El poner atención a estos componentes de la capacidad permite, a su vez, distinguir los retos y oportunidades en determinado gobierno para poder mejorar su nivel de capacidad institucional. 
En este orden de ideas se aplicaron cuestionarios a los directores de ingreso y catastro de los seis municipios estudiados, mismos que nos permitieron medir el nivel de capacidad institucional de los catastros y tesorerías para poder lograr un objetivo concreto: aumentar la recaudación predial.

El cuestionario para las direcciones de ingresos se organiza en tres apartados y busca levantar información sobre tres grandes rubros: $i$ ) elementos que afectan directamente la base tributaria (valores catastrales, y gastos fiscales); ii) recursos con que cuenta la dirección de ingresos (recursos humanos, materiales, informáticos y de tecnología de la información); iii) procesos y/o gestión para el cobro del impuesto predial (procesos de recaudación, de cobranza, de fiscalización y sanción, así como estructura organizacional).

En el caso del cuestionario sobre la capacidad administrativa del catastro, éste se organiza en tres apartados: i) valores catastrales; ii) recursos institucionales con los que cuenta el catastro para realizar sus labores; iii) gestión catastral. Lo que estos cuestionarios arrojan es una batería de indicadores que dan pie a un índice, lo cual facilita la evaluación y comparación entre tesorerías y catastros de los seis municipios.

El puntaje que resulta de las respuestas al cuestionario cuenta con un máximo de 20 puntos (20 preguntas que se responden con sí o no, para lo cual se da el valor de 1 a las respuestas afirmativas y 0 para las negativas) para medir la capacidad administrativa de las direcciones de ingreso y de 29 puntos para medir la del catastro. Las preguntas están diseñadas para que las respuestas afirmativas indiquen que las direcciones de ingresos o catastros cuentan con determinada habilidad que les estaría aportando a la construcción de sus capacidades administrativas. ${ }^{10}$ Los Cuadros 4 y 5 nos muestran los resultados.

En términos de la capacidad institucional del catastro, Mérida es el que tiene mejor nivel (con un índice de 83), le sigue Puebla. El hecho de que Xalapa es el peor calificado y que Aguascalientes no tiene catastro municipal coincide con que son también la pareja con más bajos niveles de recaudación. Por otro lado, es de sorprender que Guadalajara tenga un nivel tan pobre en su índice catastral.

En cuanto a la capacidad institucional de las direcciones de ingresos, se aprecia que la de Querétaro es la que cuenta con más elementos para cobrar el predial de manera más efectiva y eficiente, pero Mérida y Puebla no se quedan atrás en los esfuerzos realizados en estas áreas. Guadalajara muestra

${ }^{10}$ Igualmente se pueden consultar los instrumentos y sus resultados en: https://www. lincolninst.edu/es/publications/working-papers/una-hacienda-local-pobre-los-determinantesla-recaudacion-predial-en 


\section{Cuadro 4}

Índice de capacidad institucional del catastro para cobrar el predial

\begin{tabular}{lcc}
\hline \multirow{2}{*}{ Municipio } & \multicolumn{2}{c}{ Índice capacidad institucional } \\
\cline { 2 - 3 } & Catastro (base 100) & Catastro \\
\hline Querétaro & 67.2 & Medio \\
Guadalajara & 39.7 & Medio \\
Mérida & 82.8 & Alto \\
Puebla & 72.0 & Alto \\
Xalapa & 19.0 & Bajo \\
Aguascalientes & $*$ & Bajo \\
\hline
\end{tabular}

* No tiene catastro municipal.

Fuente: Elaboración propia a partir de datos proporcionados por municipios.

una capacidad institucional en su dirección de ingresos mediocre, ocupando el cuarto lugar. Xalapa y Aguascalientes son de nuevo los que reciben la calificación más baja.

Nuestros hallazgos, expresados en los Cuadros 4 y 5 , confirman que hay una relación positiva entre el nivel de capacidad institucional de los catastros y las direcciones de ingreso con el nivel de recaudación predial presentado en el Cuadro 3. Recordemos que una vez que aislamos el efecto de los valores inmobiliarios intrínsecos de cada municipio, tenemos que Mérida y Querétaro son los que más recaudan. Guadalajara y Puebla son la pareja de

\section{Cuadro 5}

Índices de capacidad institucional de direcciones de ingresos para cobrar el predial

\begin{tabular}{lcc}
\hline & \multicolumn{2}{c}{ Índice capacidad institucional } \\
\cline { 2 - 3 } Municipio & $\begin{array}{c}\text { Dirección ingresos } \\
\text { (base 100) }\end{array}$ & Dirección de ingresos \\
\hline Querétaro & 78.9 & Alto \\
Guadalajara & 65.0 & Medio \\
Mérida & 75.0 & Alto \\
Puebla & 75.0 & Alto \\
Xalapa & 31.6 & Bajo \\
Aguascalientes & 52.6 & Bajo \\
\hline
\end{tabular}

Fuente: Elaboración propia a partir de datos proporcionados por el municipio. 
media recaudación y Xalapa y Aguascalientes son catalogados como los de menor recaudación predial. En síntesis, los municipios de alta recaudación predial son los municipios con mayor capacidad institucional en sus catastros y direcciones de ingresos. Igualmente, los municipios con menor capacidad institucional presentan la recaudación predial más baja.

Las entrevistas que se condujeron con los funcionarios públicos, además de facilitar la medición de los índices de capacidad institucional, proporcionaron también información cualitativa muy rica sobre la situación de los municipios en términos de $a$ ) los recursos con que cuentan y $b$ ) de sus procesos y/o gestión para cobrar el predial. ${ }^{11}$ Por cuestiones de espacio sólo se resaltará aquí lo más importante.

Los recursos a los que se hace mención son los humanos y los tecnológicos. Sobre los primeros lo sobresaliente es la diferencia entre el personal de confianza y el sindicalizado, y la rotación del personal tan alta dados los cambios de administraciones. Varios municipios consideran que la gente sindicalizada es poco eficiente. Por ejemplo, en un municipio el director del catastro comentó sobre los sindicalizados: "lo peor es que no los puedo quitar, la única gente que me sirve es la de contrato y de confianza, la gente de sindicato es una bronca". El director de ingresos de Aguascalientes, por su parte, opina que "hay un trabajo político que hace difícil sacarle provecho a la gente de sindicato, hay mucha gente que es intocable". Por último, el director de cartografía del catastro de Guadalajara comenta que a la hora de realizar contrataciones, "las sindicalizadas están definidas por el sindicato, pero cuando es gente de confianza sí estamos más cerca, se busca más el perfil y nosotros tomamos parte en la contratación".

Por otro lado, funcionarios de varios municipios mencionaron que la rotación del personal es alta, lo que merma el nivel de profesionalismo. Como mencionaron en Xalapa: "mucho de lo que afecta es que cambian las administraciones y llega gente sin cualificaciones, llegan simplemente porque ayudaron en campañas". O como comentaron en Aguascalientes: "los alcaldes traen su gente, entonces nos ha tocado ver un desfile tremendo de jefes; para nosotros es muy difícil porque los que se van no nos autorizan nada, y los que llegan pues no conocen nada". Sobre los recursos tecnológicos, en las entrevistas queda muy claro que el contar con una infraestructura informática y tecnológica para poder tener información que permita controlar el padrón catastral y predial, y tomar decisiones informadas, es un prerrequisito para ser eficiente.

${ }^{11}$ La lista de las entrevistas realizadas a lo largo del trabajo de campo se puede consultar en: https://www.lincolninst.edu/es/publications/working-papers/una-hacienda-local-pobre-losdeterminantes-la-recaudacion-predial-en 
En cuanto al proceso del cobro de predial, éste se puede dividir en los esfuerzos de recaudación, cobranza y fiscalización. Lo que vale la pena enfatizar aquí es cómo el trato a morosos y deudores puede ser tan discrecional y fomentar el clientelismo. En un municipio, por ejemplo, la multa que se genera por ley es de $100 \%$ del impuesto, pero el director de ingresos y el alcalde tienen la atribución de dar un descuento en multas de hasta $90 \%$, mismo que se hace válido cuando la gente lo pide. Así, en los miércoles ciudadanos, "cuando cada director saca su mesita al patio del palacio municipal, la fila de la dirección de ingresos es la más larga y el director de ingresos se la pasa firmando descuentos a la gente. Tenemos descuentos en predial, en infracciones de tránsito, panteones, mercados, usos de piso, estacionamientos, en todo". Igualmente, comentan en otro municipio que "si la gente viene, le damos $40 \%$ de descuento; si chilla, $60 \%$; si chillan más, el 70 , y si vienen con una recomendación, bueno pues hasta el 80 por ciento".

\section{Los factores políticos y la recaudación}

Con el fin de detectar la influencia de los factores políticos en la recaudación predial, proponemos una lógica de escala micro que de manera detallada presta atención a tres elementos que se relacionan directamente con la recaudación: i) los valores catastrales, ii) las tasas impositivas y iii) los gastos fiscales. En función de esta lógica se construyeron los instrumentos para recabar la información cualitativa y cuantitativa que diera luz al respecto en cada municipio. El objetivo es encontrar qué es lo que determina el monto de los valores catastrales, las tasas del impuesto y los beneficios fiscales (gastos fiscales) que se otorgan en el predial.

\section{i) Valores catastrales y tasas de predial}

La recaudación predial resulta de aplicar a los valores catastrales de cada cuenta predial la tasa impositiva que le corresponde, lo que en muchos municipios llaman el "monto de facturación". El que esto se acerque al potencial máximo de recaudación depende inicialmente de dos elementos: de qué tan próximos estén los valores catastrales a los de mercado y de los montos de las tasas impositivas propuestas por el municipio y aprobadas por la legislatura estatal. ${ }^{12}$

12 Según el artículo 115 constitucional, fracción IV, el municipio puede proponer tanto las tablas de valores como las tasas y tarifas del impuesto a la legislatura estatal. En otras palabras, el municipio no tiene amplia autonomía para definir los elementos clave del impuesto: su base y su tasa. 
Por ello, es importante preguntarse qué tan actualizados están los valores catastrales, cómo se fija la tasa y qué tan razonable es ésta.

La actualización de valores catastrales para acercarlos a los valores de mercado depende de dos situaciones: $a$ ) que se haga o no una propuesta de actualización de tablas de valores que se presente a la legislatura estatal, y b) de que la propuesta sea aprobada o no por la legislatura. Nuestra hipótesis es que hacer o no una propuesta está sopesado por consideraciones políticas; es decir, los políticos considerarán actualizar valores, o subir tasas, con base en el costo político que perciban que la medida pueda tener. Igualmente, debido a como se establecen las tasas y tarifas del predial, nuestra hipótesis es que, si el gobierno estatal está en manos de un partido distinto al del alcalde, será más difícil obtener la aprobación de lo que proponga el municipio.

Los municipios de Xalapa, hasta 2013, y de Aguascalientes se pueden clasificar como los que se han caracterizado por tener un impuesto predial muy inercial. Xalapa es el que menos ha aumentado su recaudación en los últimos 23 años, aunque es necesario aclarar que está actualmente en proceso de cambio: en 2014 entró al programa Banobras-INEGI ${ }^{13}$ de modernización catastral y actualización de valores, y su recaudación de 2014 a 2015 aumentó en $23 \%$ debido a la actualización de sus valores catastrales. Según la jefa de recaudación del municipio (con veinte años de antigüedad en el gobierno), el presidente municipal actual se distingue de los demás porque "le entró a la actualización, y en cambio los otros la veían [la actualización] como un golpe político". ${ }^{14}$

Aguascalientes presenta también un comportamiento predial inercial y en su caso, presentar propuestas de actualización de valores al congreso es más improbable puesto que ahí el municipio no tiene control sobre el catastro; no existe un catastro municipal y se depende enteramente del estatal. Si a esto se le agrega que el gobierno de la entidad pertenece al Partido Revolucionario Institucional (PRI) y el municipal al Partido Acción Nacional (PAN), el propio director de ingresos de Aguascalientes juzga que es más difícil poder trabajar en equipo con el catastro estatal para presentar una propuesta de actualización de tablas de valores. Él dice: “¿Qué interés pueden tener ellos en que recaudemos más predial? No tenemos contacto con el catastro porque no lo necesitamos, porque al catastro no le interesa si nos pagan o no, eso es municipal". ${ }^{15}$

${ }^{13}$ Banco Nacional de Obras y Servicios Públicos (Banobras). Instituto Nacional de Estadística y Geografía (INEGI).

${ }^{14}$ Entrevista con Maribertha Herrera, jefa de recaudación de Xalapa, 13 de octubre del 2015.

15 Entrevista realizada el 7 de octubre de 2015. 
Otro corte de municipios es el que no hace una propuesta de actualización al congreso porque explícitamente no quiere pagar el costo político que creen que tendrá el aumento de valores. Ejemplo de este tipo de municipios es Guadalajara en la administración 2009-2012, en el que "el presidente municipal [Aristóteles Sandoval] cobró el mismo predial por tres años, por compromiso de campaña", lo que deja un "problema para la siguiente administración porque no se puede recuperar el rezago de un jalón en un año". ${ }^{16}$

Otro tipo de municipio es el que sí presenta una propuesta de tablas de valores para lograr su actualización. Una vez que esto sucede, la propuesta se puede aprobar o no. Mérida y Querétaro han tenido la experiencia de que les rechacen la propuesta en 2008 y 2009, respectivamente. En ambos casos el rechazo ha coincidido con que el partido en el poder del gobierno estatal es distinto al del gobierno municipal. ${ }^{17}$ En el caso de Mérida, para lograr la aprobación de la propuesta de tablas "se optó por sacarle la vuelta al obstáculo mediante la creación de un concejo consultivo catastral integrado por empresarios, colegios de profesionistas, sindicatos y funcionarios públicos, al que fuera más difícil rechazarle la propuesta". ${ }^{18}$

En el caso de Querétaro, el municipio interpuso una controversia constitucional en contra de la legislatura estatal. El proceso legal duró varios meses e implicó que el predial se cobrara según la legislatura lo había establecido cuando modificó la propuesta del municipio. Al final el municipio ganó y "sentó jurisprudencia bajo los argumentos de autonomía municipal, dejando claro que la legislatura sólo puede hacer modificaciones cuando haya razones fundadas y motivadas". ${ }^{19}$ En Querétaro no se optó por crear un concejo consultivo catastral para evitar futuros rechazos de la legislatura, como se hizo en Mérida, ya que las autoridades del catastro consideran "que no es conveniente que algo tan técnico deba de hacer caso a las opiniones del sector empresarial". ${ }^{20}$ Dicha postura tiene sentido si se piensa que difícilmente los intereses de las cámaras de comercio, empresariales y de la construcción van a pugnar por actualizar valores catastrales y equipararlos a los de mercado, ya que eso redundaría en un mayor pago de impuestos inmobiliarios. De nuestros casos de estudio, sólo Mérida y Guadalajara cuentan con concejos catastrales y el concejo de Guadalajara se conforma por varias cámaras del sector privado.

16 Entrevista con el personal del catastro de Guadalajara, 23 de junio de 2015.

${ }_{17}$ Conviene enfatizar que el único otro caso que presenta esta diferencia de colores en los gobiernos fue Guadalajara en la administración de Aristóteles Sandoval, quien simplemente no propuso la actualización a la legislatura "por ser un compromiso de campaña".

${ }_{18}$ Entrevista con el director del catastro de Mérida, 29 de junio de 2015.

19 Entrevista con la directora de ingresos de Querétaro, 19 de octubre de 2015.

${ }^{20}$ Entrevista con el director del catastro de Querétaro, 20 de octubre de 2015. 
En los casos en que el municipio decide hacer una propuesta de tabla de valores catastrales, la presenta al congreso estatal y éste la aprueba, se consigue la actualización de valores y que éstos se acerquen al valor de mercado lo más posible, idealmente. Esta cadena de eventos debería redundar en un aumento en la recaudación predial más o menos proporcional al porcentaje del aumento en los valores catastrales. Sin embargo, los municipios tienden a limitar este incremento mediante distintas estrategias. Algunos limitan el aumento a través de artículos transitorios en las leyes de ingresos municipales, como el incremento del predial a $10 \%$ con respecto al pago del año anterior, como lo hacen Aguascalientes y Mérida. Puebla utiliza la misma estrategia, pero el límite que plantea al incremento es de $25 \%$. Otros municipios, como Xalapa, "juegan con la tasa y la bajan para no pegarle tanto a la gente". ${ }^{21}$ Ejemplo del uso de estos topes para la recaudación es el caso de Mérida, que actualizó valores en 2013 subiéndolos en 64\%, pero el predial sólo aumentó $8 \%$ de 2012 a $2013 .^{22}$

Cuatro de los seis casos de estudio, entonces, cuentan con disposiciones en sus leyes de ingreso o similares que limitan el aumento del pago predial. En otras palabras, a pesar de la actualización de valores y de acercarlos al valor de mercado, como dicta la reforma al artículo 115 de 1999, los municipios deciden no aprovechar la actualización de valores en su totalidad, ya que consideran más importante "suavizar el impacto del aumento con los transitorios". ${ }^{23}$

Si bien, por lo que se aprecia en estos casos, la actualización de valores catastrales no rinde los frutos esperados en términos de recaudación predial (ya que capan el aumento), sí lo hace en términos de los impuestos que se cobran por la adquisición de bienes inmuebles o el traslado de domino. Estos impuestos a la propiedad sí toman en cuenta el valor catastral actualizado al $100 \%$, lo que explica por qué el ingreso de estos dos impuestos inmobiliarios ha ido al alza en los últimos años y representa, en algunos casos, un buen porcentaje de los ingresos tributarios municipales (véase la Gráfica 5). Según los comentarios de algunos tesoreros o directores de ingreso, ${ }^{24}$ no se duda en utilizar el valor catastral más actualizado como la base tributaria del impuesto, muy probablemente porque este tipo de transacciones entre particulares es menor en número que el de contribuyentes que pagan predial al año, y con ello los descontentos (precio político) son menos.

${ }^{21}$ Entrevista con el director del catastro de Xalapa, 12 de octubre de 2015.

22 Según los datos proporcionados por Mérida, el valor catastral de todas sus cuentas en 2012 fue de 147308294008 pesos, y en 2013 de 241936693402.

${ }^{23}$ Director de ingresos de Mérida.

${ }^{24}$ Entrevistas en Mérida, Aguascalientes y Xalapa. 


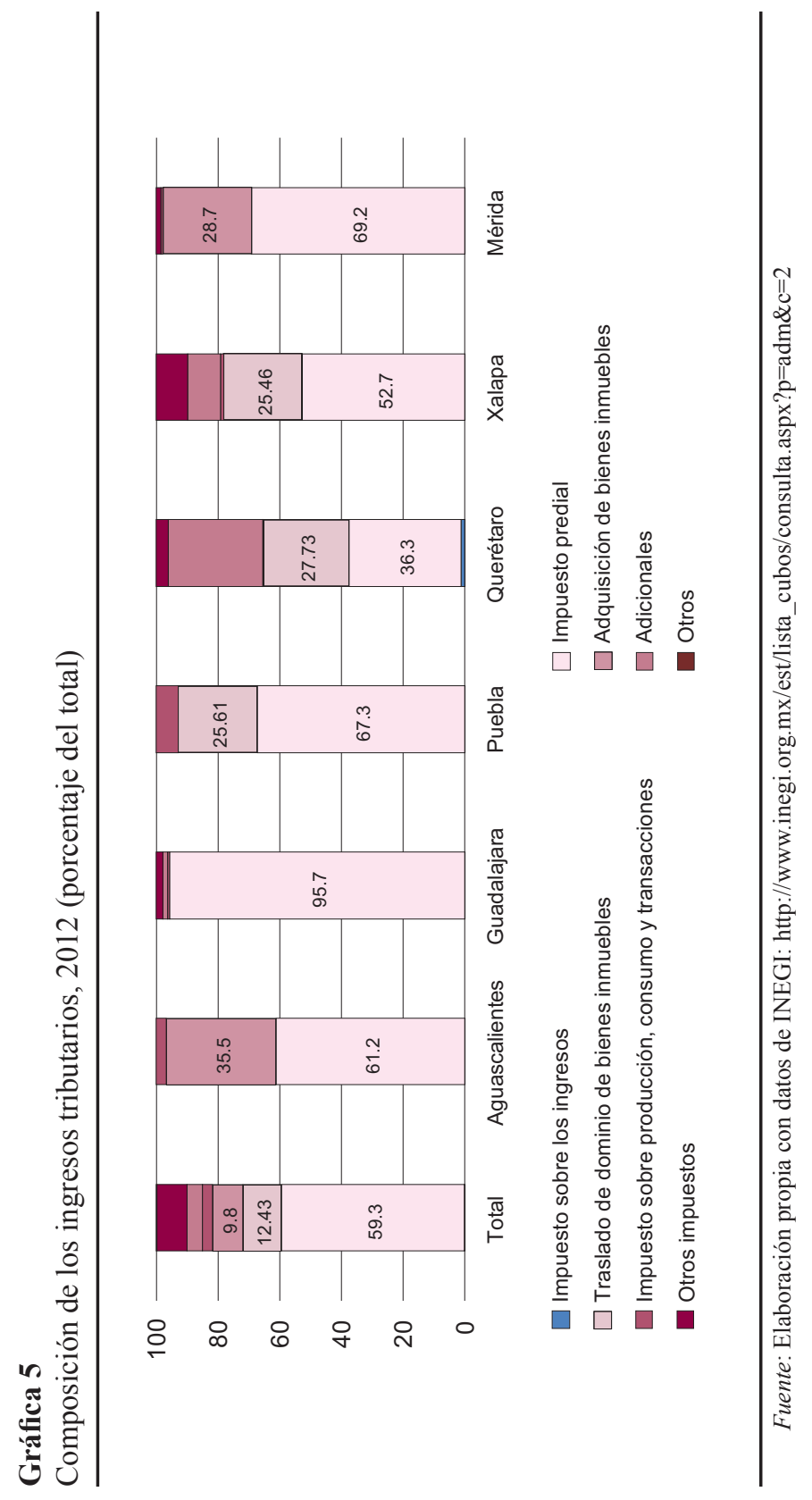


En vista de lo anterior, se puede concluir que la actualización de valores puede aumentar la recaudación predial, pero el monto del aumento no depende de la actualización en sí ni de su acercamiento a los valores de mercado, sino de cuánto del aumento de la actualización decida capitalizar el municipio en pago predial, lo que a su vez, según los funcionarios entrevistados, está permeado por consideraciones políticas. El hecho de que sí utilicen los valores actualizados para el cobro del impuesto de traslado o adquisición de dominio -que por el número de contribuyentes que lo pagan al año es menos costoso políticamente que el predial- constata que las consideraciones políticas influyen en las decisiones que toman los funcionarios municipales respecto al predial.

La relevancia de los impuestos de traslado o adquisición de inmuebles son en todos los casos el segundo impuesto más importante después del predial, excepto en el caso de Guadalajara, donde $96 \%$ de su recaudación proviene del predial. Este tipo de impuestos es muy importante para Aguascalientes (le da $36 \%$ de sus ingresos tributarios) y para los otros cuatro también, pues les aporta de 25 a $28 \%$ de su recaudación. Al menos dos hechos llaman la atención aquí: la pasividad de Guadalajara para recaudar a través de otros impuestos y el hecho de que Querétaro es un alto recaudador de predial con todo y que recauda también altos niveles por traslado de dominio e impuestos adicionales.

En cuanto a la modificación de las tasas y tarifas del predial, en el caso concreto de los seis municipios de estudio, ninguno subió o buscará subir sus tasas. Al contrario, en Xalapa el director de ingresos tenía muy claro en octubre de 2015 "que las tarifas no se van a modificar el año que entra, puesto que es año electoral". De igual manera, el director de ingresos de Aguascalientes dijo que "para el año que entra no quise aumentar el porcentaje de las tasas por dos cosas: voy a tener problemas con la ciudadanía y es año electoral". En síntesis, aumentar las tasas impositivas del predial no parece ser común y menos en años electorales, ya que los alcaldes, tesoreros y directores de ingresos calculan que existe un costo político alto y prefieren no pagarlo.

A continuación, se describirá la estructura de tasas en cada uno de los seis municipios estudiados, lo que nos permitirá apreciar la variación que existe entre los casos de estudio. Según el Cuadro 6, Mérida es el único municipio que en su estructura de tasas responde a principios de equidad y proporcionalidad. De hecho, en el país sólo 11 de las 32 capitales cuenta con un predial progresivo. Mérida tiene una estructura de tasas progresiva con cuotas fijas y tasas marginales; considera dos bases: el valor catastral y la contraprestación por arrendamiento aplicando el impuesto a la 
base que implique el mayor monto. En cambio, los demás municipios imponen una tasa única a cualquier predio, independientemente del valor del mismo.

Algunos municipios, como Aguascalientes, Guadalajara, Querétaro y Puebla, aplican una tasa más alta a los predios baldíos o sin construcción, lo que busca desincentivar el especular con la tierra, no tener terrenos ociosos cuando hay necesidades de desarrollo habitacional y evitar que los baldíos se conviertan en focos de infección (basureros al aire libre). En cuanto al uso de los predios o inmuebles, sólo Aguascalientes aplica una tasa especial para los predios comerciales, de servicios o industriales. De hecho, sólo ocho capitales del país diferencian entre predios habitacionales y comerciales, aplicándoles una tasa diferente. Sin embargo, esto ha abierto la puerta para que los contribuyentes que pagan una tasa más alta disputen el tratamiento que se les da y se amparen tratando de no pagar. Bajo esta lógica, Aguascalientes, que es el municipio que tiene tasas diferenciadas según el tipo de inmueble, sufre de muchas demandas de amparo interpuestas generalmente por los contribuyentes grandes. ${ }^{25}$

El Cuadro 7 busca hacer evidente la diferencia de tasas en cada municipio y sus implicaciones para la recaudación. La tasa única más alta la tiene Puebla (1.8\%), le sigue Querétaro (1.6\%) y luego Guadalajara (1.524\%). Mérida, en contraste, es el municipio que recauda menos de los inmuebles de menor valor ( 86 pesos) y más de aquellos más costosos (1 890 pesos); es decir, es el único que tiene una estructura de tasas progresiva.

En conclusión, este apartado ha demostrado, principalmente a través de la información vertida en las entrevistas, que la modificación de las tasas al alza, la actualización de valores catastrales y la capitalización de dicha actualización para aumentar la recaudación del impuesto, dependen de consideraciones políticas. Igualmente, con los casos de Xalapa, Querétaro y Mérida observamos que al pertenecer a diferentes partidos el gobierno estatal y el municipal, el desempeño recaudatorio del municipio puede ser afectado, pues el gobierno estatal puede dificultar la aprobación de las tablas de valores o tasas que proponen los municipios y, en el caso de tener el control del catastro, puede presentar rezagos en los valores catastrales tales que mermen la recaudación.

${ }^{25}$ Entrevista con el director de ingresos de Aguascalientes, 7 de octubre de 2015. 


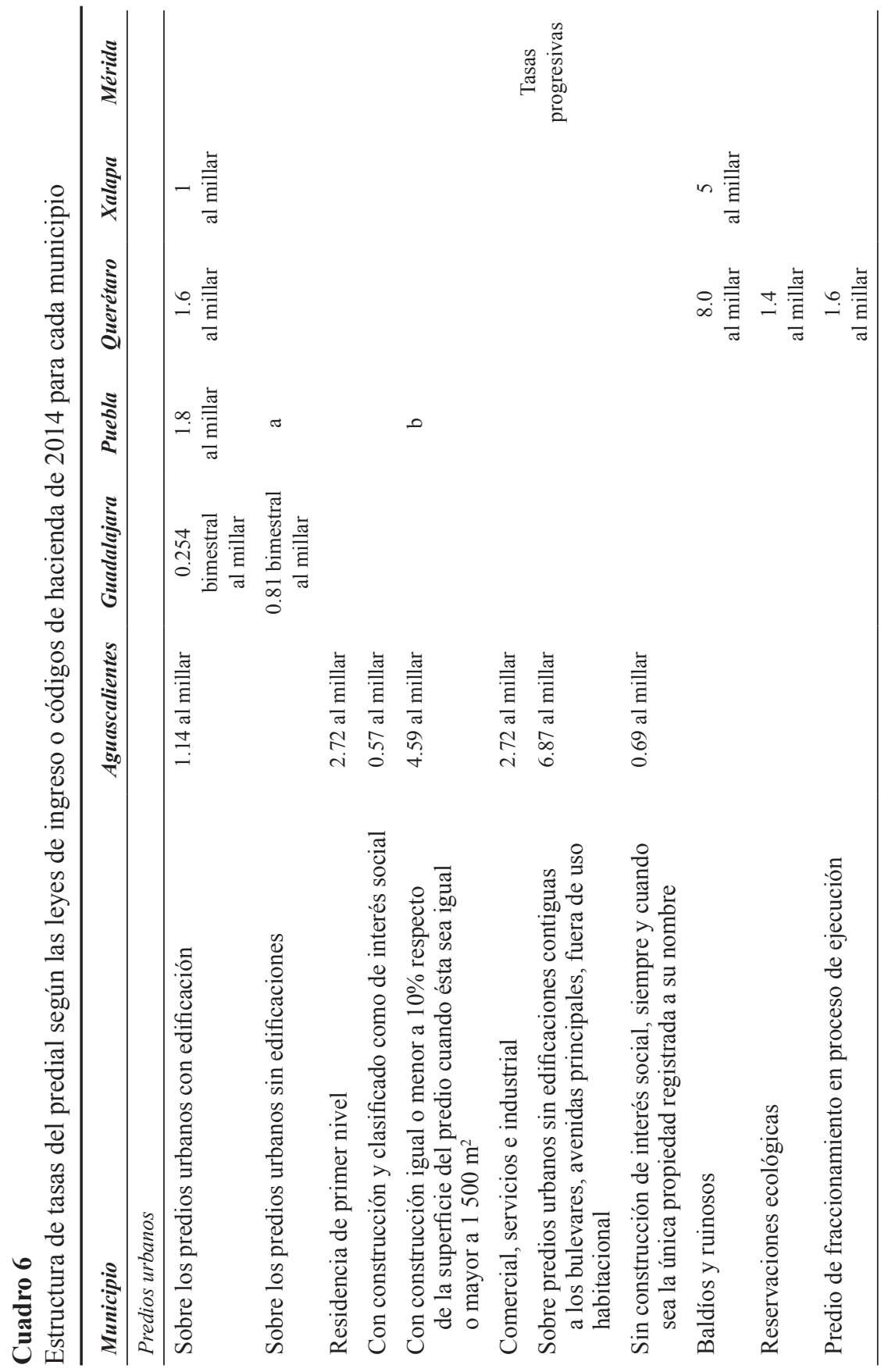




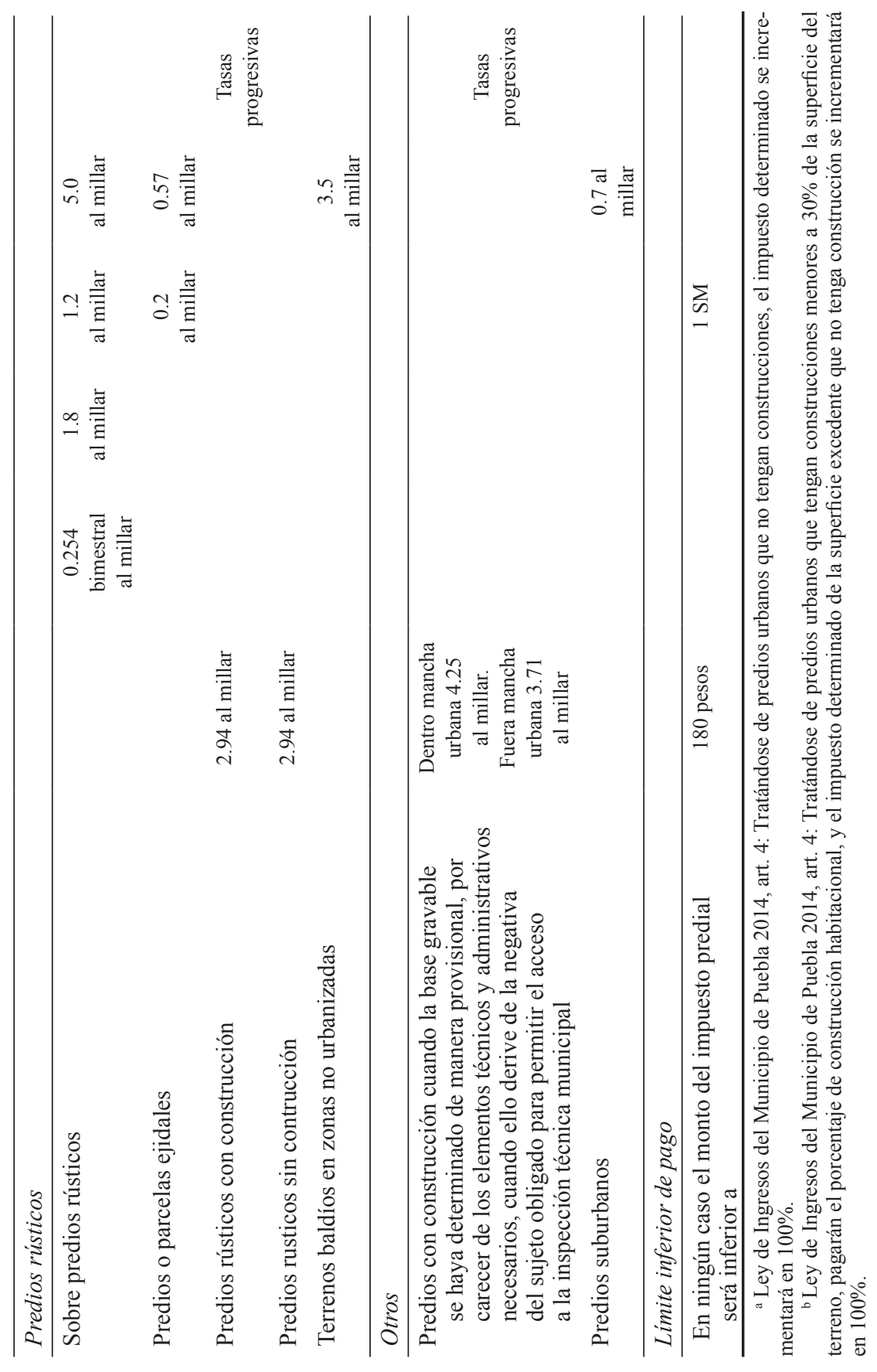




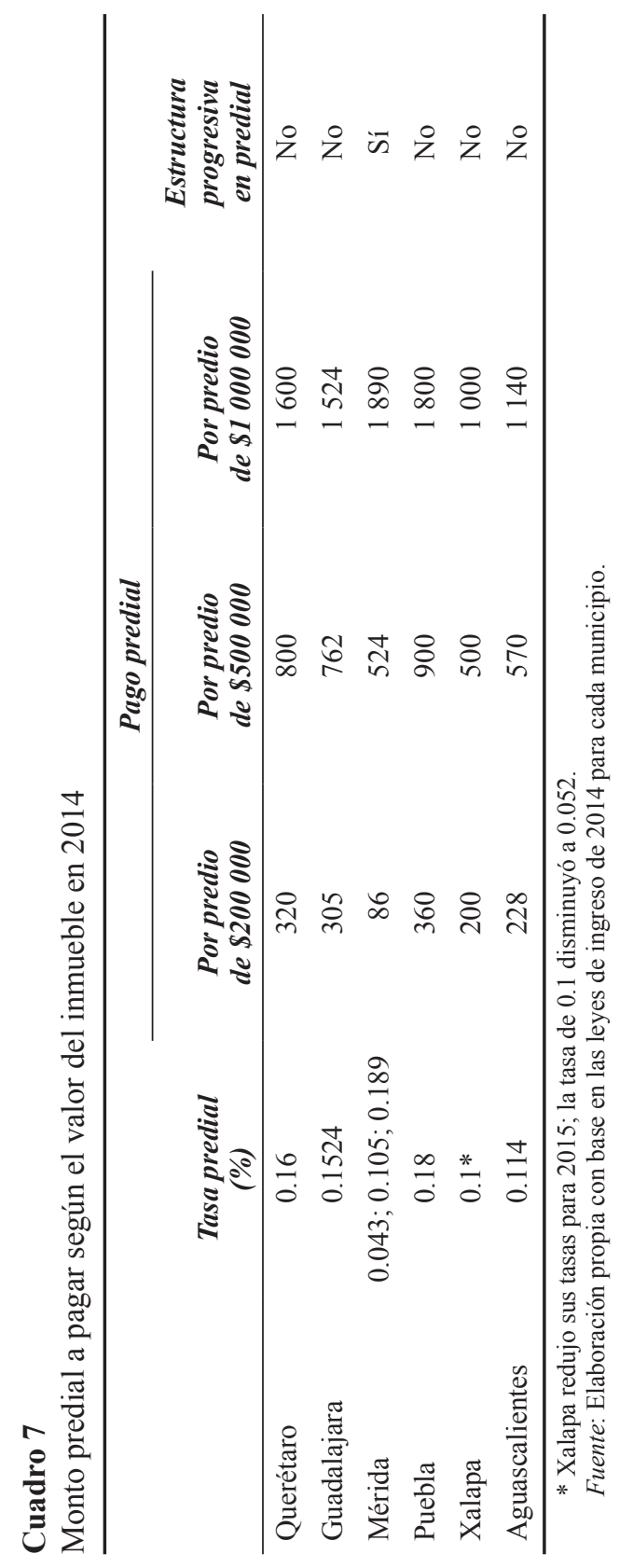




\section{ii) Gastos fiscales}

La recaudación del predial -y de cualquier impuesto-puede disminuirse por el efecto de los gastos fiscales. Los gastos fiscales son el monto de impuesto no cobrado debido a "los tratamientos que se desvían de la estructura normal de los impuestos considerando las disposiciones fiscales vigentes" (SHCP, 2012). Mientras más gastos fiscales, menos recaudación. Mientras más exenciones, descuentos, beneficios y tratamientos especiales, menos recaudación. ${ }^{26}$ Lo que hace relevante preguntar: ¿qué explica el nivel de los gastos fiscales en un municipio?, ¿cuál es el objetivo que persiguen éstos y qué tan eficaces son estos gastos en alcanzar su objetivo?.

Con base en la información obtenida en el trabajo de campo se sugiere que los gastos fiscales son $i$ ) el resultado de un comportamiento populista por parte de quienes los pueden establecer y/o ii) el resultado de la falta de capacidad institucional que se refleja en no evaluar técnicamente el costobeneficio de los gastos fiscales para definir su creación, continuidad o eliminación.

En teoría, los beneficios fiscales y tratamientos preferenciales son incentivos fiscales que están planteados en función y con el fin de alcanzar objetivos concretos de política pública. Normalmente estos objetivos, en el caso del predial, persiguen metas como la progresividad impositiva, la mejora en la eficiencia recaudatoria, la preservación del medio ambiente y del patrimonio arquitectónico, el impulso cultural y de actividades recreativas, y el impulso a sectores económicos, entre otros. Un gasto fiscal implica un costo en términos de recaudación perdida, sin embargo, también puede significar un beneficio en términos del logro del objetivo para el cual se diseñó.

Por ello, es importante que se evalúen los gastos fiscales de cualquier nivel de gobierno mediante un análisis costo-beneficio para decidir introducirlos, mantenerlos o cancelarlos. Lo ideal sería que un análisis de esta naturaleza diera pie a dichos incentivos fiscales; no obstante, según los entrevistados, este procedimiento no es el que se sigue en nuestros municipios (y muy probablemente tampoco en la mayoría de los del país). De hecho, en nuestros seis casos de estudio, al solicitarles la información, no contaban con los datos sobre el monto que representan los gastos fiscales. Los datos que se obtuvieron se generaron expresamente al hacerles la petición de información.

26 Para conocer un listado con todos los conceptos de gasto fiscal que se contemplan en las leyes de ingresos y hacienda o códigos hacendarios de 2014 de los municipios estudiados, véase la tabla 20 en: https://www.lincolninst.edu/sites/default/files/pubfiles/unda_wp$17 \mathrm{mu} 1 \mathrm{sp} . \mathrm{pdf}$ 
En el mismo sentido, los funcionarios entrevistados en los seis municipios no parecían ser conscientes de este tipo de ejercicios de análisis técnico para evaluar la pertinencia de los beneficios fiscales y tratamientos especiales, y perciben como algo per se positivo o benevolente el concederlos. Basta como ejemplo la siguiente cita del director de ingresos de Aguascalientes: “¿Por qué si a una compañía que genera 5000 empleos le damos hasta el aire, al chiquito no? Ésa es mi pelea, a ellos hay que darles también cinco años de exención".

Guadalajara es por mucho el municipio que más disposiciones de gasto fiscal tiene (20); mientras que en Puebla sólo hay tres motivos que dan pie a gastos fiscales en el predial. Los seis municipios exentan del impuesto a los inmuebles del dominio público de cualquier nivel de gobierno, a menos que no se usen con fines públicos. Los conceptos de gasto fiscal más comunes en los municipios de México son los descuentos otorgados por pronto pago y aquellos otorgados a grupos que se consideran vulnerables. Teniendo en mente el caso de Guadalajara, hay que considerar que el abuso de incentivos fiscales en un impuesto puede inducir una pérdida de la conciencia colectiva del pago de tributos. Asimismo, es posible que algunos de los incentivos fiscales, más que generar un bien colectivo o una ganancia social, pueden resultar más bien en beneficios otorgados a ciertos grupos de interés.

Cinco de los seis municipios ofrecen descuento en el pago predial por pronto pago. Al ofrecer el descuento se está incentivando que el contribuyente realice el pago sin que se le tenga que requerir, lo que libera recursos que de otro modo estarían dedicados al esfuerzo de cobranza. El promedio de descuento que ofrecen las capitales estatales del país es de $10 \%$, por lo que Querétaro, Mérida y Xalapa se aprecian como "generosos" en este rubro al ofrecer el $20 \%$ por pagar en enero, y cabe preguntarse si vale la pena. Puebla parece no ofrecer descuentos por pronto pago. Sin embargo, hay que considerar que existen disposiciones fiscales en los municipios que no están registradas en las leyes de ingreso, leyes de hacienda o códigos fiscales, sino que provienen de alguna disposición o decreto puntual del ejecutivo. Es decir, un presidente municipal puede, de manera espontánea y poco formal, otorgar algún beneficio fiscal que impacta la recaudación, pero que es difícil rastrear en leyes o códigos.

Otro tipo de descuento muy común ahora en los municipios mexicanos es el ofrecer $50 \%$ de rebaja en el pago predial a personas de la tercera edad (60 años y más), viudas, pensionadas y jubiladas, como lo hacen Xalapa, Aguascalientes, Guadalajara y Querétaro. ${ }^{27}$ Puebla parece no otorgar este tipo

27 Querétaro da el mismo descuento a discapacitados. Guadalajara "premia" con descuentos según la edad: a los contribuyentes de 75 años les da $60 \%$ de descuento, y a los de más de 80 años, el $80 \%$. 
de descuentos. En teoría, este tipo de incentivos responden al objetivo de progresividad impositiva pues suponen a tales grupos como de menores ingresos, lo cual no siempre es el caso y por ello algunos municipios condicionan el descuento a que se reciba en sólo una de las propiedades del contribuyente y topan el valor del inmueble que pueda ser sujeto de descuento. Según los datos proporcionados por los municipios al requerirles la información, en 2015 los gastos fiscales por descuentos a grupos vulnerables y por pronto pago representaron en Xalapa 20\% de su recaudación predial, en Aguascalientes $14 \%$ y en Mérida 9.5\%. Desafortunadamente los municipios de Guadalajara y Querétaro no proporcionaron datos sobre sus gastos fiscales.

\section{Conclusiones}

El análisis de los seis estudios de caso, representativos de los 50 municipios que concentran $34 \%$ de la población que vive en condiciones de desarrollo por encima del promedio y han experimentado alternancia, nos permite concluir que la capacidad institucional de los gobiernos municipales y los factores políticos influyen en el nivel de recaudación predial. Cabe reiterar que estos hallazgos, basados en evidencia principalmente cualitativa, coinciden con los resultados de estudios econométricos (Broid, 2010; Unda, 2017) que encuentran una correlación negativa entre la competencia electoral y la recaudación predial, lo que sugiere que los funcionarios municipales, al percibir mayor probabilidad de perder las elecciones, prefieren comportarse de manera populista y no aumentar la recaudación.

Los índices que se construyeron para medir los niveles de capacidad institucional de tesorerías y catastros sugieren que sí hay una correlación positiva entre la capacidad institucional y el nivel de recaudación predial. Querétaro y Mérida son quienes presentan los niveles más altos de capacidad en ambas dependencias y quienes más recaudan. Por otro lado, Xalapa y Aguascalientes, que son los que menos recaudan, presentan también los peores índices. Es más, Aguascalientes no cuenta con catastro municipal y depende enteramente del estatal. Entre los factores que distinguen la capacidad institucional de Mérida y Querétaro están los buenos recursos tecnológicos con los que cuentan (sistemas únicos de gestión catastral) y el interés por analizar a profundidad la morosidad de los contribuyentes. Mérida sobresale por tener comunicación con el contribuyente a través de campañas informativas y de concientización de pago tributario, y Querétaro está abierto a llevar la fiscalización hasta sus últimas consecuencias: el embargo. 
Para observar la posible influencia de los factores políticos en la recaudación predial se propuso, desde una lógica de escala micro, que la recaudación predial se relacione directamente con los valores catastrales, las tasas impositivas y los gastos fiscales. En cuanto a los valores catastrales, se encontró que el que éstos se actualicen o no, y que en su caso tal actualización se capitalice en su totalidad en recaudación predial, depende de consideraciones políticas por parte de los tomadores de decisiones municipales. Los municipios no hacen propuestas para actualizar los valores en sus respectivos congresos pues "fue un compromiso de campaña" no hacerlo. En el mejor de los casos, cuando se logra la actualización de valores, la mayoría de los municipios optan por limitar el incremento del predial que correspondería, ya sea capando el aumento a un porcentaje o disminuyendo la tasa tributaria. Este hallazgo contraviene la idea popularmente extendida de que la recaudación predial es baja porque los valores no están actualizados. Estos casos demuestran que el realizar actualizaciones de valores no garantiza aumentos de predial. El hecho de que dichas actualizaciones sí se capitalizan en los impuestos por adquisición o traslado de inmuebles confirma también que las consideraciones políticas son relevantes para tomar estas decisiones tributarias. Los impuestos por transacciones inmobiliarias, por ser más quirúrgicos en términos del impacto negativo en los contribuyentes que el que tiene el aumento por actualizaciones, sí son aprovechados por los municipios.

Al igual que sucede con la decisión de actualizar los valores catastrales y de capitalizarlos en una mayor recaudación, el elevar las tasas impositivas está sujeto a cálculos políticos. Aumentar la tasa del predial no es una medida comúnmente utilizada, y es claro que, de acuerdo con los tomadores de decisión, debe evitarse en año electoral. El análisis de Xalapa, Querétaro y Mérida mostró que al pertenecer a diferentes partidos el gobierno estatal y el municipal, el desempeño recaudatorio del municipio puede ser afectado, pues el gobierno estatal podría dificultar la aprobación de las tablas de valores o tasas que proponen los municipios. Y, en el caso de que el estado tenga el control del catastro, esto puede conllevar rezagos en los valores catastrales que acaben afectando la recaudación. En cuanto al panorama que se describió en términos de las estructuras de tasas en los municipios, se distingue que existe un espacio de mejora en cuanto a la progresividad en las tasas. ${ }^{28}$ Cinco de los seis municipios manejan tasas únicas y no diferencian

${ }^{28}$ Esta sugerencia se fundamenta en que el predial es un impuesto directo con amplio potencial recaudatorio y distributivo debido a sus múltiples ventajas, a saber: su base (propiedad inmobiliaria) es altamente visible y no móvil (Seligman, 1895, pp. 54-63); el valor de los predios no fluctúa como los ingresos (Bahl y Martinez-Vaquez, 2007, pp. 2-4); lo pagan únicamente los propietarios de los inmuebles, y de tener tasas que aumenten conforme incremente el valor del 
entre los inmuebles dedicados a la vivienda y los de uso económico. Mérida es el único con una estructura de tasas progresivas.

El análisis de los gastos fiscales permite resaltar varios puntos. La variación en los seis municipios en cuanto al uso de gastos fiscales es amplia. Guadalajara, con el riesgo de abusar y alejarse de una cultura de responsabilidad tributaria, es el que más beneficios y tratamientos preferenciales otorga (20 según sus leyes). En cambio, Puebla es el que concede menos gastos fiscales, pues sólo otorga tres. Los recursos perdidos por estas disposiciones no son algo trivial. Sólo en el caso de los recursos no recaudados debido a descuentos otorgados a grupos vulnerables y por pronto pago tenemos que Xalapa, Aguascalientes y Mérida perdieron en 2015 el 20, 14 y 9.5\% de su recaudación predial, respectivamente. Los funcionarios entrevistados de todos los municipios observados no están conscientes de la importancia de cuantificar y evaluar la pertinencia de los gastos fiscales; en ningún caso se realizan análisis costobeneficio que definan la introducción, permanencia o eliminación de los gastos fiscales, a pesar de que, como todo gasto, deberían de estar ampliamente justificados. A partir de lo observado y de la información vertida en entrevistas, se concluye que los gastos fiscales otorgados en cada municipio responden a la falta de capacidad institucional municipal, reflejada específicamente en el bajo nivel de profesionalismo y habilidades técnicas de los recursos humanos. Y se sugiere que la concesión de gastos fiscales puede ser entendida como una decisión política diseñada para ser populistas con el contribuyente.

El estudio y análisis que se hizo en estos seis municipios, generalizable a los 50 municipios más poblados del país con un nivel de desarrollo económico arriba del promedio y experiencia en alternancia política, permite apuntar varios espacios de mejora si es que se quiere aumentar la recaudación predial. Primero, la actualización de valores catastrales no debería de "caparse" (o no en la medida que lo hacen) para aminorar el impacto fiscal. Segundo, los municipios podrían aprovechar la progresividad que el predial ofrece si se establece con tasas progresivas y diferenciando por tipo de predio. Tercero, la pertinencia de los gastos fiscales debe de ser evaluada a través de análisis de costo-beneficio y en consecuencia mantenerlos o eliminarlos. Cuarto, se requiere fortalecer la capacidad institucional de los catastros y direcciones de ingresos, en especial mediante la profesionalización de los recursos humanos y la creación o aprovechamiento de recursos tecnológicos. Quinto, es importante fomentar la relación entre gobierno y contribuyentes a través de campa-

predio pueden ser altamente progresivos (Gaffney, 1972, pp. 139-141; De Cesare, 2012). Aunque cabe anotar que el establecer tasas progresivas o diferenciadas por tipo de predio (como en Aguascalientes) puede abrir la puerta a amparos interpuestos por los contribuyentes que argumentan recibir un trato diferenciado. 
ñas imaginativas de información y concientización sobre temas impositivos, pues ello tiene el potencial de aumentar la recaudación. Pero sobre todo, el diseño y la gestión del predial y de su proceso de cobro deben estar aislados de consideraciones políticas y ser el resultado de un ejercicio técnico. De no contar con esta independencia, y sabiendo que los impuestos son impopulares por naturaleza, será muy difícil aumentar la recaudación.

\section{Bibliografía}

Banxico. (varios años). Ingresos y gastos presupuestales del sector público. Recuperado del sitio de internet del Banco de México: http://www.banxico.org.mx/ SieInternet/consultarDirectorioInternetAction.do?accion=consultarCuadro\&id Cuadro $=$ CG1\&sector $=9 \&$ locale $=$ es

Banxico. (varios años). Producto interno bruto a precios corrientes (anual). Recuperado del sitio de internet del Banco de México: www.banxico.org.mx/Sie Internet/consultarDirectorioInternetAction.do?accion=consultarCuadro\&id Cuadro $=$ CR $74 \&$ sector $=2 \&$ locale $=$ es

Best, M. (1976). Political power and tax revenues in Central America. Journal of Development Economics, 3(1), pp. 49-82. Recuperado de http://www.sciencedirect.com/science/article/pii/0304387876900407

Bahl, R. y Martinez-Vazquez, J. (2007). The property tax in developing countries: Current practice and prospects (Documento de trabajo, núm. 07RB1). Cambridge, MA: Lincoln Institute of Land Policy.

Bird, R. y Casanegra, M. (eds.). (1992). Improving tax administration in developing countries. Washington DC: International Monetary Fund.

Broid Krauze, D. (2010). La evolución predial en México: incentivos cruzados de la descentralización fiscal y política 1990-2007 (Tesis de licenciatura, ITAM, Ciudad de México).

Burgess, R. y Stern, N. (1993). Taxation and development. Journal of Economic Literature, 31(2), pp. 762-830. Recuperado de http://personal.lse.ac.uk/ sternn/074NHS.pdf

Bustamante Quintana, N. (2001). Impuesto predial en Hermosillo, Sonora. Estudios Demográficos y Urbanos, 16(2), pp. 415-439. Recuperado de http://estudios demograficosyurbanos.colmex.mx/index.php/edu/article/view/1124/1117

Canavire-Bacarreza, G. y Zúñiga, N. (2015). Transferencias e impuesto predial en México. Economía UNAM, 12(35), 69-99. Recuperado de http://www.scielo. org.mx/pdf/eunam/v12n35/1665-952X-eunam-12-35-00069.pdf

Cruz Vásquez, M. (2011). Causas de la baja recaudación del impuesto predial en el estado de Oaxaca. El efecto de los usos y costumbres. Ponencia presentada en el XVI Congreso Internacional de Contaduría, Administración e Informática, Ciudad de México, 5 a 7 de octubre. 
De Cesare, C. (2012). Improving the performance of the property tax in Latin America. Cambridge, MA: Lincoln Institute of Land Policy.

Di John, J. (2006). The political economy of taxation and tax reform in developing countries (Documento de trabajo, núm. 2006/74.UNU-WIDE). Tokio, Japón: United Nations University.

Gaffney, M. (1972). What is property tax reform? American Journal of Economics and Sociology, 31(2), pp. 132-152. Recuperado de http://www.jstor.org/stable/ 3485632

Hilderbrand, M., Grindle, E. y Merilee S. (1997). Building sustainable capacity in the public sector. What can be done? En M. S. Grindle (ed.), Getting good government. Capacity building in the public sectors of developing countries. Boston, MA: Harvard University Press.

Hinrichs, Harley H. (1966). A general theory of tax structure change during economic development. Cambridge, MA: Harvard Law School.

Ibarra, J. y Sotres, L. (2009). Determinantes de la recaudación del impuesto predial en Tamaulipas: instituciones y zona frontera norte. Frontera norte, 21(42), 165 192. Recuperado de http://www.scielo.org.mx/pdf/fn/v21n42/v21n42a7.pdf

Ibarra, J. y Sotres L. (2013). Las instituciones fiscales como paliativo para enfrentar crisis financieras: el impuesto predial en el estado de Coahuila. En J. E. Mendoza (coord.), La crisis financiera internacional. Efectos sectoriales en México y en su frontera. Tijuana: Colegio de la Frontera Norte.

Ibarra, J. y Sotres, L. (2014). Diferencias en la recaudación del impuesto predial en la zona fronteriza: evidencia en los municipios de Chihuahua. Estudios Demográficos y Urbanos, 29(1), pp. 53-87. Recuperado de http://estudiosdemograficos yurbanos.colmex.mx/index.php/edu/article/view/1455/1448

INEGI. (1990a). Información sobre los ingresos gubernamentales. Aguascalientes: Instituto Nacional de Estadísticas y Geografía.

INEGI. (1990b). Estadísticas históricas de México. Aguascalientes, Instituto Nacional de Estadística y Geografía.

INEGI. (1991). Finanzas públicas estatales y municipales de México, 1979-1988. Aguascalientes: Instituto Nacional de Estadística y Geografía

INEGI. (varios años). Finanzas públicas estatales y municipales. Recuperado de la página de internet del Instituto Nacional de Estadística y Geografía: http://www. inegi.org.mx/est/contenidos/proyectos/registros/economicas/finanzas/

INEGI. (varios años). Índices de precios. Recuperado de la página de internet del Instituto Nacional de Estadística y Geografía: www.inegi.org.mx/est/contenidos/ proyectos/inp/default.aspx

INEGI. (varios años). PIB y cuentas nacionales de México. Recuperado de la página de internet del Instituto Nacional de Estadística y Geografía: http://www.inegi. org.mx/est/contenidos/proyectos/cn/

INEGI. (varios años). Consulta interactiva de datos. Recuperado de la página de internet del Instituto Nacional de Estadística y Geografía: http://www.inegi.org. $\mathrm{mx} /$ est/lista_cubos/ 
INEGI. (varios años). Censos y conteos de población y vivienda. Recuperado de la página de internet del Instituto Nacional de Estadística y Geografía: http://www. inegi.org.mx/est/contenidos/proyectos/ccpv/

Lotz, J. R. y Morss, E. R. (1970). A theory of tax level determinants for developing countries. Economic Development and Cultural Change, 18(3), 328-341. Recuperado de http://www.jstor.org/stable/1152062?seq=1\#page_scan_tab_contents

Musgrave, R. (1969). Fiscal systems. New Haven: Yale University Press

OECD (varios años). Revenue statistics database. Recuperado de la página de internet de la Organización para la Cooperación y el Desarrollo Económicos: https:// stats.oecd.org/Index.aspx?DataSetCode=REV

OECD. (varios años). Revenue satistics in Latin America. Recuperado de la página de internet de la Organización para la Cooperación y el Desarrollo Económicos: www.oecd-ilibrary.org/taxation/revenue-statistics-in-latin-america-2014 9789264207943-en-fr

Ortiz, D. (2001). México: banco de datos. Ciudad de México: El Inversionista Mexicano.

Peña Ahumada, J. A. y Wence, L. A. (2011). La distribución de transferencias federales para municipios, ¿qué incentivos se desprenden para el fortalecimiento de sus haciendas públicas? Hacienda Municipal, 115, 79-96. Recuperado de http:// www.inafed.gob.mx/work/dso/la_distribucion_de_transferencias_federales para_municipios.pdf

Raich, U. (2001). Impacts on expenditure decentralization on Mexican local governments (Documento de trabajo, núm. 102). México: CIDE-DAP.

Ruelas Ávila, I. (2010). Análisis del impuesto predial en México (Tesis de maestría, Universidad de Chile, Santiago de Chile).

Seligman, E. R. A. (1895), Essays in taxation. Nueva York y Londres: Macmillan.

SHCP. (2012). Presupuesto de gastos fiscales, 2012. Recuperado de la página de internet de la Secretaría de Hacienda y Crédito Público: http://www.shcp.gob. $\mathrm{mx} /$ INGRESOS/Ingresos_pres_gasto/pres_gast_fis_2012.pdf

SHF. (varios años). Estadísticas de vivienda. Recuperado de la página de internet de la Sociedad Hipotecaria Federal: http://doc.shf.gob.mx/estadisticas/EstadViv InformaAvaluos/Paginas/default.aspx

Silva Herzog, J. (1982). Diario de debates de la Cámara de Diputados, 49 [Legislatura LII, año 1, periodo ordinario, 11 de diciembre de 1982]. Recuperado de http:/cronica.diputados.gob.mx/DDebates/52/1er/Ord/19821211.html

Sour, L. (2004). El sistema de transferencias federales en México, ¿premio o castigo para el esfuerzo fiscal de los gobiernos locales urbanos. Gestión y Politica Pública, 13(3), 733-751. Recuperado de http://www.gestionypoliticapublica. cide.edu/num_anteriores/Vol.XIII_NoIII_2dosem/LauraSour.pdf

Sour, L. (2008). Un repaso de los conceptos sobre capacidad y esfuerzo fiscal y su aplicación en los gobiernos locales mexicanos. Estudios Demográficos y Urbanos, 23(2), 271-297. Recuperado de http://estudiosdemograficosyurbanos. colmex.mx/index.php/edu/article/view/1312/1305 
Tanzi, V. (2000). Taxation in Latin America in the last decade (Documento de trabajo, núm. 76). Stanford, CA: Center for Research on Economic Development and Policy Reform.

Unda Gutiérrez, M. (2017). Una hacienda local pobre: los determinantes de la recaudación predial en México (Documento de Trabajo, WP17MU1SP). Cambridge, MA: The Lincoln Institute of Land Policy. Recuperado de https://www.lincolninst. edu/sites/default/files/pubfiles/unda_wp17mu1sp.pdf

Unda Gutiérrez, M. y Moreno-Jaimes, C. (2015). La recaudación del impuesto predial: un análisis de sus determinantes económicos en el periodo 1969-2010. Revista Mexicana de Ciencias Politicas y Sociales, 60(225), 53-84. Recuperado de http:// www.redalyc.org/articulo.oa?id=42141200003

Zúñiga Espinoza, N. G. (2010). Transferencias condicionadas e impuesto predial para los municipios de Sinaloa, México. Dimensión Económica, 1(3). Recuperado de http://www.journals.unam.mx/index.php/rde/article/view/21548

Zurllkanian, D. Alias B. y Muthuveerappan, Ch. (2008). The needs for capacity building in local government in Malaysia. Ponencia presentada en International Real Estate Research Symposium 2008: Benchmarking, Innovation and Sustaining Real Estate Market Dynamics, Kuala Lumpur, Malasia, 30 de abril.

\section{Acerca de la autora}

Mónica Unda Gutiérrez es profesora investigadora en el Centro de Estudios Demográficos, Urbanos y Ambientales de El Colegio de México, A.C. Obtuvo el doctorado y la maestría en Estudios para el Desarrollo por la Universidad de Londres (LSE y SOAS, respectivamente). Ha impartido los cursos de Teoría del Desarrollo, Finanzas Públicas y Economía Política Urbana a nivel maestría y licenciatura. Es miembro del Sistema Nacional de Investigadores. Su investigación se centra en las finanzas municipales y la economía política de los impuestos en México. Tiene interés particular por la trayectoria de los impuestos directos como el predial y el impuesto sobre la renta.

Fecha de recepción: 21 de marzo de 2017.

Fecha de aceptación: 9 de enero de 2018. 
